\title{
Assessing the sensitivities of a distributed snow model to forcing data resolution
}

Article

Published Version

Winstral, A., Marks, D. and Gurney, R. (2014) Assessing the sensitivities of a distributed snow model to forcing data resolution. Journal of Hydrometeorology, 15 (4). pp. 13661383. ISSN 1525-7541 doi: https://doi.org/10.1175/JHM-D-130169.1 Available at https://centaur.reading.ac.uk/39209/

It is advisable to refer to the publisher's version if you intend to cite from the work. See Guidance on citing.

Published version at: http://dx.doi.org/10.1175/JHM-D-13-0169.1

To link to this article DOI: http://dx.doi.org/10.1175/JHM-D-13-0169.1

Publisher: American Meteorological Society

All outputs in CentAUR are protected by Intellectual Property Rights law, including copyright law. Copyright and IPR is retained by the creators or other copyright holders. Terms and conditions for use of this material are defined in the End User Agreement.

\section{www.reading.ac.uk/centaur}

\section{CentAUR}

Central Archive at the University of Reading

Reading's research outputs online 


\title{
Assessing the Sensitivities of a Distributed Snow Model to Forcing Data Resolution
}

\author{
ADAM WINSTRAL AND DANNY MARKS \\ Agricultural Research Service, USDA, Boise, Idaho \\ ROBERT GURNEY \\ University of Reading, Reading, United Kingdom
}

(Manuscript received 7 October 2013, in final form 11 February 2014)

\begin{abstract}
Highly heterogeneous mountain snow distributions strongly affect soil moisture patterns; local ecology; and, ultimately, the timing, magnitude, and chemistry of stream runoff. Capturing these vital heterogeneities in a physically based distributed snow model requires appropriately scaled model structures. This work looks at how model scale-particularly the resolutions at which the forcing processes are represented-affects simulated snow distributions and melt. The research area is in the Reynolds Creek Experimental Watershed in southwestern Idaho. In this region, where there is a negative correlation between snow accumulation and melt rates, overall scale degradation pushed simulated melt to earlier in the season. The processes mainly responsible for snow distribution heterogeneity in this region-wind speed, wind-affected snow accumulations, thermal radiation, and solar radiation-were also independently rescaled to test process-specific spatiotemporal sensitivities. It was found that in order to accurately simulate snowmelt in this catchment, the snow cover needed to be resolved to $100 \mathrm{~m}$. Wind and wind-affected precipitation- the primary influence on snow distribution-required similar resolution. Thermal radiation scaled with the vegetation structure $(\sim 100 \mathrm{~m})$, while solar radiation was adequately modeled with $100-250-\mathrm{m}$ resolution. Spatiotemporal sensitivities to model scale were found that allowed for further reductions in computational costs through the winter months with limited losses in accuracy. It was also shown that these modeling-based scale breaks could be associated with physiographic and vegetation structures to aid a priori modeling decisions.
\end{abstract}

\section{Introduction}

In alpine watersheds, large heterogeneities in snow distribution are often observed over very small distances. Large snowdrifts can be found on leeward slopes just downwind from wind-exposed ridges with minimal snow accumulations (Luce et al. 1998; Winstral and Marks 2002). In forested regions, interception and subsequent sublimation of snow from forest canopies strongly affect snow distribution (Pomeroy and Gray 1995; Trujillo et al. 2007). Spatially variable energy fluxes-primarily radiation (Elder et al. 1991) and turbulent (Prowse and Owens 1982; Pohl et al. 2006) exchanges-add additional complexity to snow distributions. This heterogeneity of snow cover strongly affects mountain runoff (Luce et al. 1998; Winstral and Marks 2002), soil moisture (Seyfried et al.

Corresponding author address: Adam Winstral, USDA-ARSNWRC, 800 Park Blvd., Suite 105, Boise, ID 83712.

E-mail: adam.winstral@ars.usda.gov
2009), vegetation cover (Ishikawa 2003), microbial activities (Jones 1999), and nutrient cycling (Bowman 1992; Brooks and Williams 1999). Oftentimes, these heterogeneities occur at scales of tens of meters (Deems et al. 2006; Trujillo et al. 2007), which poses a dilemma in largescale snow models. Resolving these features requires either explicit representations with a high-resolution model or reliance on a means of statistically capturing the subgrid heterogeneity in a lower-resolution solution. The former comes with extensive computational demands. The latter is replete with compromises, as it is impossible to fully capture the spatial complexities and nonlinear processes that affect snow distributions with statistical modeling.

Extensive research has been conducted describing the scaling characteristics of snow distributions. A review of much of this work follows. However, to our knowledge, none has directly assessed the scaling characteristics of the primary processes that ultimately control snow accumulation and melt. Cline et al. (1998) did evaluate 
how scaling of the energy fluxes affected snow distributions. Their work, however, rescaled all processes together, and the analysis was limited to the melt period after peak snow water equivalent (SWE). In this paper, we examine the sensitivity of modeled accumulation and melt to variously scaled representations of each of the primary forcing processes to quantify the consequences of mismatched model and process scales throughout the snow season.

A snow cover energy- and mass-balance model (ISNOBAL; Marks et al. 1999b), which has been extensively applied and tested throughout the world, is used to perform this model-based analysis. Physically based distributed and semidistributed snow models are currently being applied on an operational basis over increasingly larger regions with widely ranging model resolutions. These models require distributed meteorological forcings. In most applications, the resolution of both the forcing processes and model outcomes are consistent. Computation times and memory requirements for calculating distributed forcings-particularly for the more physically complex processes such as radiation fluxes and wind-affected snow accumulations-are similar in magnitude to those of the energy-balance snow model alone. We propose that not all of the forcing processes require similar levels of detail at all times to accurately simulate snow distribution and melt and that substantial reductions in computation times can be achieved with minor losses in model effectiveness. The results presented here should be broadly applicable to all physically based, explicit snow models reliant on spatially distributed forcings.

We present a direct assessment of how model resolution affects representations of the primary processes that control accumulation and melt in this research basin-wind, wind-affected snow accumulations, solar radiation, and thermal radiation-and how these scale effects propagate to simulated snow distributions and surface water inputs. We test a multitude of gridded model resolutions $(10-1500 \mathrm{~m})$ covering the range frequently encountered in modeling applications and remote sensing products. The following analysis presents insights into potential scale-based model biases as well as potential means for reducing the computational costs of distributed snow models.

\section{Background}

Prior studies have addressed the scale behavior of snow cover variability. Of particular interest has been capturing the length scale or correlation length-the distance at which the variance does not increase substantially with increasing distance between measurements. This is a measure of what is commonly referred to as processscale variability. In order for a model to capture processscale variability, either the resolution of the model (i.e., model scale) must be finer or the model must contain a means, usually statistical in nature, of capturing these subelement processes. These earlier studies provide context on the level of detail required for representing snow distributions. The snow observations, however, are the product of many interacting processes. Prior scaling analyses by Trujillo et al. (2007) and Deems et al. (2006) have implicitly associated differences in snow cover heterogeneity patterns with primary forcing processes via the similar scaling behaviors of snow fields and process-associated structural controls (e.g., topographic and vegetative structure as the controlling factors on wind redistribution and interception/radiation, respectively). However, to our knowledge, no prior work has directly addressed the scaling properties of the forcing processes. The prior scale-related research on snow distributions provided valuable insights and guidance for this research, and a brief review follows.

Early insights on snow distribution scaling behavior were based on labor-intensive and costly manual surveys that, because of logistics, costs, and potential avalanche danger, were often limited in some spatial context. Shook and Gray (1996) found that the transition from autocorrelated to random behavior, also referred to as correlation length, occurred at $30 \mathrm{~m}$ on flat land and increased with the large-scale topographic variability in open, exposed, low-relief prairie and arctic environments. Kuchment and Gelfan (2001) analyzed snowdepth distributions along long transects $(15-20 \mathrm{~km})$ at a sampling resolution ( $20 \mathrm{~m}$ at a minimum), much coarser than considered by Shook and Gray (1996). Perhaps because of the lack of fine resolution data, Kuchment and Gelfan (2001) determined that their data were entirely self-similar, exhibiting continually increasing variability at greater length scales. Investigators have also examined snow course and Snowpack Telemetry (SNOTEL) data where correlation lengths on the order of hundreds of kilometers were observed (Ling et al. 1995; Dressler et al. 2006). Snow course and SNOTEL data, however, are sparsely located, and these sites tend to have homogeneous site characteristics (i.e., windprotected forest openings). Remotely sensed data have also been used to gain insights on snow cover variability. Blöschl (1999) used snow-covered-area patterns as indicators of SWE and showed that correlation lengths depended on measurement scales. Blöschl (1999) found that correlation lengths in the Kühtai catchment (Austria) were on the order of $100 \mathrm{~m}$ based on $5-\mathrm{m}$ pixels. In the Sierra Nevada (United States), however, Blöschl (1999) showed entirely self-similar behavior in an analysis 
of 30-m Landsat Thematic Mapper (TM) data, while a correlation length of $30 \mathrm{~km}$ was estimated from Advanced Very High Resolution Radiometer (AVHRR) 110-m data.

Many of the aforementioned studies did not contain sufficient data to adequately represent the finescale heterogeneities that directly impact mountain hydrology and ecosystems. The recent advent of lidar technology has elucidated these finer scaled details. Deems et al. (2006) used fractal analysis and found scale breaks (i.e., important breaks in scale behavior that can be analogous to correlation length) ranging from 15.5 to $40.3 \mathrm{~m}$ at three Colorado (United States) sites. They concluded that the scaling characteristics of snow depths were controlled by the spatial distribution of vegetation topography (i.e., elevation plus vegetation height) when interception was the main control on snow distribution. Where redistribution was dominant, the interaction of winds with terrain features and vegetation structure controlled the scaling characteristics. They also surmised, as did Shook and Gray (1996), that correlation length increased with increasing relief. Trujillo et al. (2007) analyzed power spectral densities at five Colorado sites, two of which were part of the Deems et al. (2006) study. They found scale breaks on the same order as those published by Deems et al. (2006), Shook and Gray (1996), and others. In contrast to Deems et al. (2006), they found no similarities in the scale behavior of snow depth, topography, or vegetation topography. They did conclude that similarities in scale behavior existed between snow depth and vegetation height at nonredistribution sites and that breaks in scale occurred at larger lengths than vegetation height-scale breaks when redistribution was prevalent.

Distributed mass and energy-balance snow models and computing resources have advanced to the stage where it is now possible to provide near-real-time products to operational forecasters covering large areas with millions of model elements. The Snow Data Assimilation System (SNODAS) is the National Weather Service's $1-\mathrm{km}$ gridded physically based mass- and energy-balance snow model with data assimilation capabilities run at an hourly time step across the entire United States (Barrett 2003; Carroll et al. 2001). ISNOBAL, a two-layer distributed snow model, has been used recently to provide high-resolution (50- and $100-\mathrm{m}$ grids) SWE products to water managers in two western U.S. river basins (Winstral and Marks 2013). The Swiss Federal Institute for Forest, Snow and Landscape Research runs an operational snowhydrological service with short-term melt forecasts based on data assimilation and a distributed snowmelt model at 1-km resolution for all of Switzerland (T. Jonas 2013, personal communication).

Distributed snow models all require distributed forcing data. Computational demands in terms of both time and storage capacities for deriving the distributed forcing data are generally greater than those of running the snow model. Most applications have applied a single spatial model scale throughout the model run from forcings to outcomes. Scale choices are often a function of data availability and the balance between computational costs and resources. This work addresses not only how these choices affect and potentially bias results but also presents means of limiting computational costs via optimized scaling decisions related to the primary forcings. Furthermore, whereas all of the earlier observational studies provided scaling snapshots for single moments in time, this modeling exercise will shed light on the temporal dependencies of scale behavior.

\section{Study area}

Dobson Creek is a headwater catchment in the Reynolds Creek Experimental Watershed (RCEW) in southwestern Idaho (United States). This study focuses on the upper portion of the Dobson Creek catchment, where snow dominates the winter landscape (Fig. 1). The lower elevations in Dobson Creek have an ephemeral snowpack throughout the winter. The research area of upper Dobson Creek has an elevation range of 1760 $2244 \mathrm{~m}$ MSL and covers an area of $6.2 \mathrm{~km}^{2}$. The catchment has a predominance of sagebrush and shrubs $(55 \%)$ on south-facing and wind-exposed slopes, with fir $(20 \%)$ and quaking aspen $(25 \%)$ dominant on north-facing slopes. Prevailing winds out of the west-southwest produce large snowdrifts on east- and northeast-facing slopes while scouring wind-exposed slopes. Snow heterogeneity is very high in large part because of the strongly windaffected patterns. Patterns in upper Dobson Creek are similar to those found in the nearby Reynolds Mountain East and Upper Sheep Creek catchments, where it has been extensively detailed that, in order to accurately predict streamflow patterns, the heterogeneity in snow distributions must be accounted for (Kumar et al. 2013; Luce et al. 1998; Winstral and Marks 2002; Winstral et al. 2013).

Data from two meteorological stations (Fig. 1) located near the bottom (1817 m MSL) and top (2170 m MSL) of the research area were used to derive the ISNOBAL forcings. Precipitation, wind speed and direction, air temperature, relative humidity, and incoming solar radiation measured at each site were used in this application. The precipitation data were undercatchcorrected using the dual-gauge correction method 


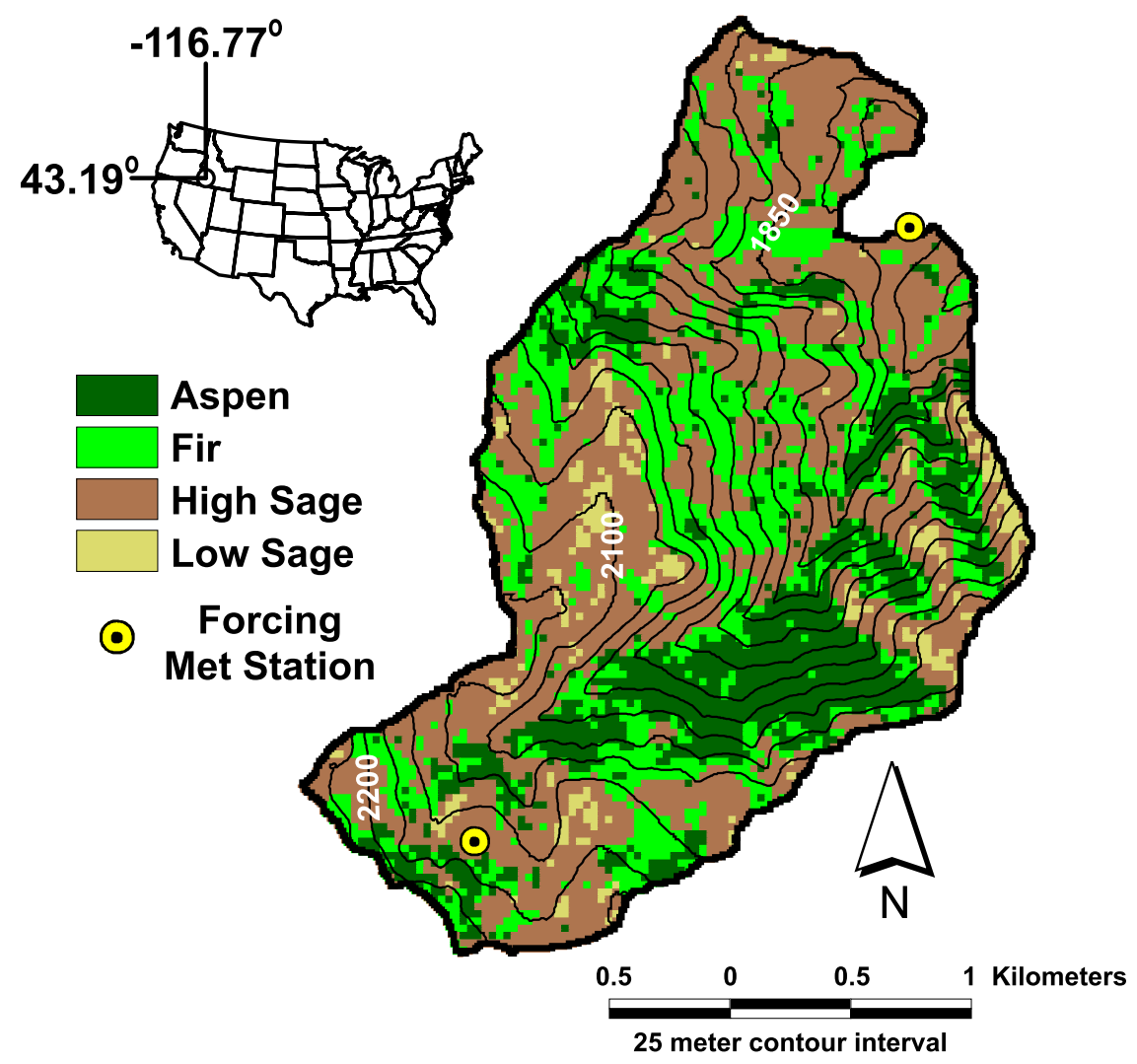

FIG. 1. Vegetation and topography in upper Dobson Creek. Fir and aspen predominate on lee and north-facing slopes; sagebrush prevails on drier, sun-exposed slopes.

(Hanson et al. 2004). Simulations took place over the course of the 2005/06 snow season, which was wetter than average and featured a large rain-on-snow event in late December, detailed in Marks et al. (2013).

\section{Methods}

Based on the prior snow distribution work and extensive snow modeling in two adjacent RCEW watersheds-Reynolds Mountain East (e.g., Winstral and Marks 2002; Winstral et al. 2013) and Upper Sheep Creek (e.g., Luce et al. 1998; Prasad et al. 2001; Winstral et al. 2013) - 10-m grid elements were used as the basis for comparisons. It has been shown that the 10-m grid scale sufficiently captured the hydrologically relevant heterogeneities of snowmelt in these two basins (Winstral and Marks 2002; Winstral et al. 2013). Snow distributions in both basins, similar to those in upper Dobson Creek, are strongly influenced by winds and exhibit a high degree of variability. The $10-\mathrm{m}$ grid scale is also finer than the scale breaks observed in prior snow-depth studies, where it has been suggested that model scales must be lower than the observed scale breaks in order to explicitly resolve the distributions (e.g., Deems et al. 2006).
The distributed mass- and energy-balance snow model used to investigate scale effects in this study was ISNOBAL (Marks et al. 1999a,b), a two-layer snow model designed for applications over digital elevation model (DEM) grids. Based on the work of Anderson (1976), ISNOBAL uses site-specific topographic and vegetation structure, with climate and precipitation data to solve the energy balance, calculate the mass balance, and track the energy state of the snow cover at each grid cell. ISNOBAL is forced with distributed fields of net solar radiation, incoming thermal radiation, air temperature, vapor pressure, soil temperature, wind speed, and precipitation. Clear sky solar radiation was calculated based on the topographically corrected solar radiation over snow (STOPORAD) model, which is the snow-covered version of the topographicallycorrected solar radiation (TOPORAD) model (Dozier 1980; Dozier and Frew 1981; Dubayah 1994). Clear sky thermal radiation was calculated based on Marks and Dozier (1979). Both solar and thermal clear sky values were adjusted for cloud cover using techniques described in Garen and Marks (2005) and for canopy effects based on Link and Marks (1999). Solar albedos were a function of grain growth and sun angle (Marshall and Warren 
1987; Warren and Wiscombe 1980; Wiscombe and Warren 1980), further reduced for late season litter accumulations (Hardy et al. 2000; Melloh et al. 2001) using a method similar to Garen and Marks (2005). Observed air temperatures and relative humidities were distributed using hourly observed lapse rates from the two weather stations to obtain distributed temperatures and vapor pressures. Distributed wind speeds were derived using the Sx terrain variable as described in Winstral et al. (2009). Wind-affected snow accumulations were accounted for in the precipitation forcing fields using both the $\mathrm{Sx}$ and $\mathrm{Sb}$ terrain variables as described in Winstral et al. (2013). Both the wind and wind-affected precipitation routines were developed at RCEW. Surface water input (SWI), which includes snowmelt, rain passing through an isothermal snow cover, and rain falling on bare ground, was simulated at each grid cell. Lateral flow within the snowpack is not considered in the model. ISNOBAL was run at a 1-h time step with daily outputs. All of the initial modeling was conducted with a 10-m gridscale DEM derived from standard U.S. Geological Survey contours by a commercial company (Peerless Management Systems, Springfield, Oregon). Comprehensive descriptions and further details of ISNOBAL can be found in Marks et al. (1999a,b).

ISNOBAL model runs were conducted over the entire Dobson Creek catchment $\left(14.4 \mathrm{~km}^{2}\right)$ in the 2005/06 and 2006/07 snow seasons. Comprehensive validation data for both model runs can be found in Winstral (2011). Validation data for the 2005/06 season-selected for this research because of its higher snow volume-can also be found in Winstral et al. (2013). The 2005/06 simulations were validated with continuous snow depths at six meteorological stations $(\overline{\mathrm{RMSE}}=11.4 \mathrm{~cm})$ and twice monthly, manually sampled SWE $(\overline{\mathrm{RMSE}}=55.8 \mathrm{~mm})$ at six snow courses in and around the Dobson Creek catchment. Nash-Sutcliffe efficiency coefficients for the snow depth and SWE time series were generally greater than 0.80 at the monitored sites. There was also excellent correspondence between the snow cover pattern simulated on 10 May 2006 and observations derived from Landsat TM satellite imagery acquired on the same date.

In the first part of this analysis, the sensitivity of simulated SWI over the entire snow season to forcing process model resolutions was evaluated. SWI consisted of the daily averaged SWI from all pixels in the basin. Initially, the model scales of all forcing processes were simultaneously rescaled, akin to Cline et al. (1998). The initial $10-\mathrm{m}$ grid scale was sequentially degraded to 30 , $100,250,500,750,1000$, and $1500 \mathrm{~m}$. Coarser grid resolutions consisted of the average of all 10-m cells enveloped by the larger cell. Next, the sensitivity of SWI to the scaling of singular processes was evaluated. The primary processes affecting accumulation and meltsolar and thermal radiation, wind, and wind-affected snow accumulations-were altered independently while all other processes were kept at the base model resolution of $10 \mathrm{~m}$. Since ISNOBAL requires a single model scale for all inputs, the coarser-resolution products were resampled back to the base model scale of $10-\mathrm{m}$. All $10-\mathrm{m}$ grid elements occurring within a scale-degraded cell received the same value (i.e., the mean of all $10-\mathrm{m}$ cells within the larger cell) in order to maintain the intended scale degradations. Simulations were initiated on 1 October 2005 with no snow on the ground and continued through complete meltout.

Snowmelt dynamics throughout the winter and spring were evaluated for the variously scaled scenarios. The focus of this work is on the effects of model scale on basinwide SWI. In small basins such as upper Dobson Creek, SWI inputs are closely correlated to stream responses, especially during spring runoff when soils are relatively moist (e.g., Winstral and Marks 2002; Winstral et al. 2013). For purposes of evaluating basinwide SWI, the larger-scaled simulations were clipped back to the 10-m grid-defined catchment boundary to preserve the catchment area across comparisons. Basin-averaged values such as these, however, can often mask underlying, compensating errors. Analyses of the spatiotemporal differences in accumulation and melt at the root of the basinwide SWI results are presented, but only to add depth to the basin-averaged observations. Readers are guided to Winstral (2011) for further insights into the spatiotemporal dynamics of scale-based influences on snow distributions and melt in this catchment. A discussion section follows the results in which scale sensitivities identified in the model analysis are 1) compared to the scaling characteristics of physiographic and vegetative features in the catchment and 2) used to test variably scaled models designed to optimize accuracy and computational efficiency.

\section{Results}

\section{a. Solar radiation}

First, the effects of solar radiation model scale were assessed. Not surprisingly, the scaled representations of solar fluxes had very little effect on simulated SWI throughout the winter, when sun angles were low (Fig. 2a). Biases and errors attributable to scale became evident in mid-March as sun angles increased and the role of solar energy on net energy exchanges correspondingly increased. As the solar radiation resolution was coarsened, simulations had increasingly positive SWI biases through the first half of the primary spring 
a) Solar Degraded

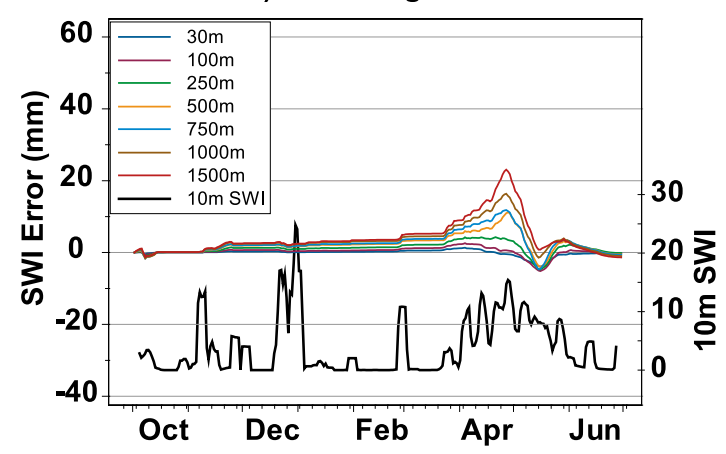

c) Wind Degraded

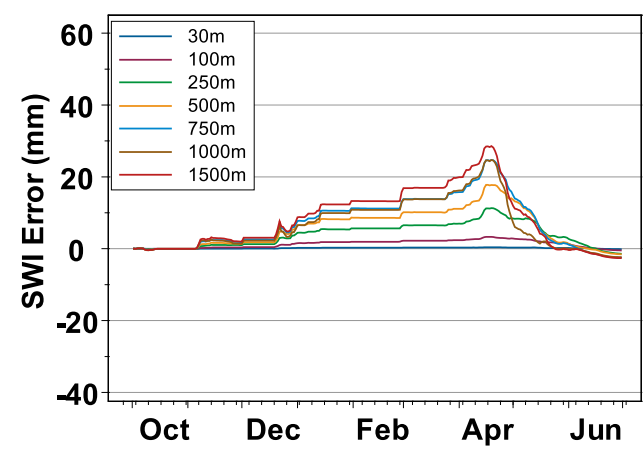

b) Thermal Degraded

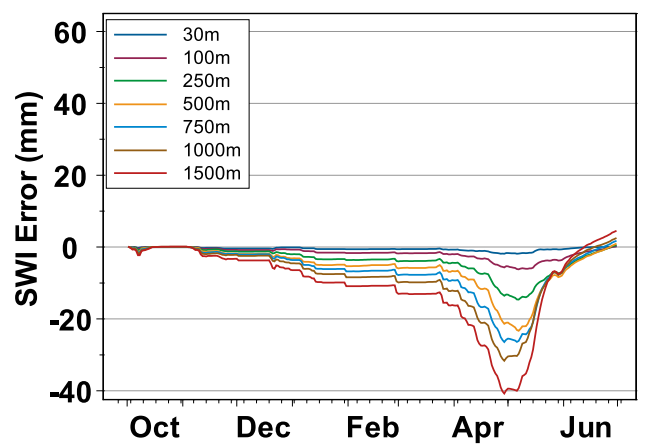

d) Precipitation and Wind Degraded

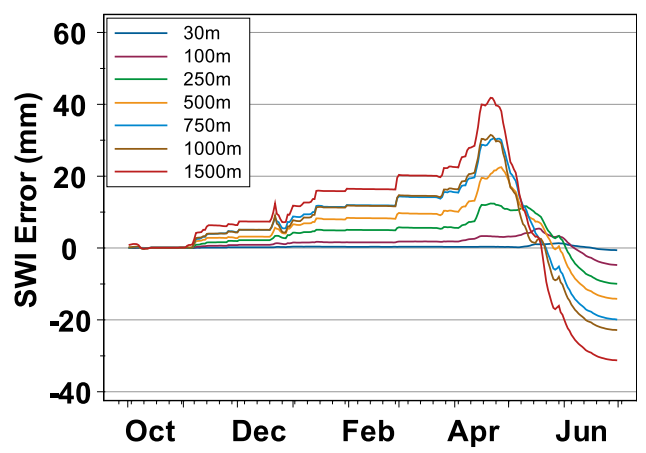

e) All Degraded

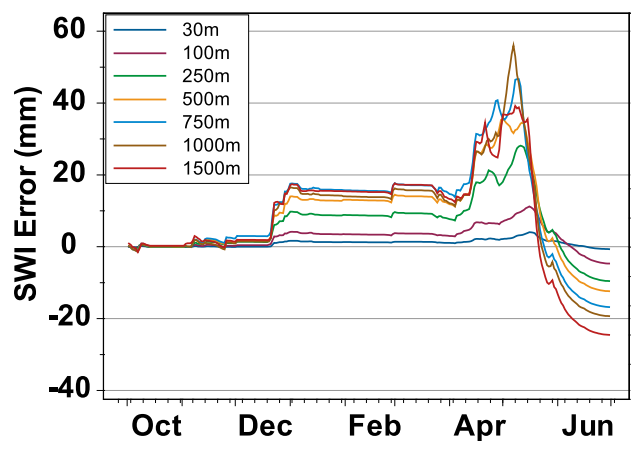

FIG. 2. (a)-(e) Cumulative SWI errors/biases for each of the degraded forcing scenarios. The 5-day averaged 10-m all-forcings SWI output is also included in (a) so that errors can be associated with the timing of runoff events.

snowmelt period (i.e., melt production greater than the $10-\mathrm{m}$ simulation) as overestimated solar inputs in shaded locations produced earlier melt. The 30-m through 250-m simulations produced only small, brief increases in SWI bias at the onset of spring melt prior to becoming negligible to slightly negative in early April. On the other hand, positive errors continued for the 500-1500-m resolutions through late April. Precipitation fluxes remained constant across all scales, producing consequent negative biases on the falling limb of the main snowmelt period in response to the scaleinduced shifts to earlier snowmelt. The positive-negative cycle was repeated, albeit to a much smaller degree, in mid- to late May.
A 9-day period on the rising limb (19-27 April) and a 17-day span on the falling limb (28 April to 14 May) of the main spring snowmelt period were chosen to gauge the magnitude of scale-induced errors compared to total SWI production. These periods were roughly when scale-induced errors were the greatest. On the rising limb, errors/biases relative to the 10-m simulated SWI were less than $1 \%$ for the $30-250-\mathrm{m}$ simulations (Table 1 ). Biases were $3 \%-6 \%$ for the $500-1000-\mathrm{m}$ simulations and $10.3 \%$ for the $1500-\mathrm{m}$ simulation. Negative bias percentages were of greater magnitude on the falling limb than the positive percentages on the rising limb (Table 2). Whereas little difference in basin-averaged simulated SWI was seen between the 100- and 250-m resolutions on 
TABLE 1. Basin-averaged SWI biases/errors on the rising limb of spring snowmelt for scaled inputs. Model scale is in the top row, the rescaled processes are in the left column, and the period analyzed is in parentheses. Biases/errors are in millimeters and are expressed as a percentage of cumulative totals over time period.

\begin{tabular}{|c|c|c|c|c|c|c|c|}
\hline & $30 \mathrm{~m}$ & $100 \mathrm{~m}$ & $250 \mathrm{~m}$ & $500 \mathrm{~m}$ & $750 \mathrm{~m}$ & $1000 \mathrm{~m}$ & $1500 \mathrm{~m}$ \\
\hline \multirow[t]{2}{*}{ Solar (19-27 Apr) } & -0.6 & 0.6 & 0.0 & 4.3 & 3.1 & 4.9 & 8.8 \\
\hline & $-0.1 \%$ & $-0.1 \%$ & $0.0 \%$ & $5.0 \%$ & $3.6 \%$ & $5.7 \%$ & $10.3 \%$ \\
\hline \multirow[t]{2}{*}{ Thermal (19-27 Apr) } & -0.8 & -2.2 & -5.5 & -8.4 & -8.5 & -9.3 & -11.7 \\
\hline & $-0.1 \%$ & $-2.6 \%$ & $-6.4 \%$ & $-9.7 \%$ & $-9.8 \%$ & $-10.1 \%$ & $-13.6 \%$ \\
\hline \multirow[t]{2}{*}{ Wind (13-16 Apr) } & 0.1 & 0.6 & 2.9 & 4.4 & 5.2 & 4.5 & 4.8 \\
\hline & $0.1 \%$ & $0.9 \%$ & $4.5 \%$ & $6.9 \%$ & $8.2 \%$ & $7.1 \%$ & $7.5 \%$ \\
\hline \multirow[t]{2}{*}{ Precipitation and wind (13-16 Apr) } & 0.0 & 0.8 & 4.6 & 6.4 & 9.1 & 9.5 & 11.5 \\
\hline & $0.0 \%$ & $1.2 \%$ & $7.2 \%$ & $10.1 \%$ & $14.4 \%$ & $15.0 \%$ & $18.2 \%$ \\
\hline \multirow[t]{2}{*}{ All forcings (13-16 Apr) } & 0.8 & 2.1 & 7.4 & 11.6 & 13.6 & 12.2 & 14.8 \\
\hline & $1.2 \%$ & $3.3 \%$ & $11.7 \%$ & $18.4 \%$ & $21.5 \%$ & $19.2 \%$ & $23.4 \%$ \\
\hline
\end{tabular}

the rising limb, slight differences were evident on the falling limb.

Since basin-averaged statistics can conceal underlying errors, SWE and SWI distributions were also assessed. A summary of distributed SWE errors from 24 April, near the apex of spring snowmelt production, is presented in Table 3. The mean errors and mean absolute errors presented in Table 3 are based on comparisons to the $10-\mathrm{m}$ product. Though only one value of SWE existed in the larger pixels, the error grid had varying errors at every $10-\mathrm{m}$ pixel contained in the larger pixel based on the various $10-\mathrm{m}$ values differenced from the larger pixel value. While mean errors are reflective of the basin-averaged results, absolute errors provide a means of quickly assessing the role that increasing yet counteracting spatial errors may have on the basinaveraged analyses. In cases with similar basin-averaged errors, the presence of higher mean absolute errors (MAEs) is indicative of modeling weaknesses.

In the solar radiation scenarios, negative SWE biases corresponding to the positive SWI biases observed on the rising limb of melt production predominate (Table 3 ). Though the absolute SWE errors at peak accumulation leveled off as grid size increased, the basin snow volume continued to decrease in response to the scale-induced increases in SWI prior to peak accumulation. Decreases in snow volume reached $7 \%$ in the $1000-\mathrm{m}$ simulation and $9 \%$ in the $1500-\mathrm{m}$ simulation. A precursor to the differences between the $100-$ and $250-\mathrm{m}$ simulations that only became apparent on the falling limb of SWI production can be seen in their differing SWE biases.

Figure 3a presents the spatial distribution of SWI errors for the entire month of April for the 1000-m solar simulation. In the upper basin, positive SWI errors were associated with tree stands. Because of the semiarid nature of this catchment, these tree stands are also on predominantly solar-shaded slopes. Increasingly coarser model resolutions encompassed more south-facing, treeless slopes into the solar flux calculations. Smoothing increased simulated fluxes in these solar-shaded domains. In combination with the thermal enhancing forest cover still modeled with $10-\mathrm{m}$ resolution, melt rates substantially increased in these areas. The greater the fraction of southfacing, treeless slopes within the larger pixel was, the greater the solar enhancement was also. These conditions were apparent in the southwestern-most pixel in Fig. 3a.

TABLE 2. Basin-averaged SWI biases/errors on the falling limb of spring snowmelt for scaled inputs. Model scale is in the top row, the rescaled processes are in the left column, and the period analyzed is in parentheses. Biases/errors are in millimeters and are expressed as a percentage of cumulative totals over time period.

\begin{tabular}{|c|c|c|c|c|c|c|c|}
\hline & $30 \mathrm{~m}$ & $100 \mathrm{~m}$ & $250 \mathrm{~m}$ & $500 \mathrm{~m}$ & $750 \mathrm{~m}$ & $1000 \mathrm{~m}$ & $1500 \mathrm{~m}$ \\
\hline \multirow[t]{2}{*}{ Solar (28 Apr to 14 May) } & -3.1 & -5.3 & -8.0 & -14.0 & -15.9 & -17.3 & -21.7 \\
\hline & $-1.7 \%$ & $-2.9 \%$ & $-4.4 \%$ & $-7.7 \%$ & $-8.8 \%$ & $-9.5 \%$ & $-11.9 \%$ \\
\hline \multirow[t]{2}{*}{ Thermal (10-22 May) } & 1.0 & 2.1 & 5.1 & 11.9 & 14.5 & 16.7 & 24.7 \\
\hline & $1.0 \%$ & $2.1 \%$ & $5.1 \%$ & $11.8 \%$ & $14.4 \%$ & $16.6 \%$ & $24.5 \%$ \\
\hline \multirow[t]{2}{*}{ Wind (23 Apr to 13 May) } & -0.0 & -0.8 & -3.2 & -8.8 & -14.6 & -20.1 & -18.7 \\
\hline & $0.0 \%$ & $-0.4 \%$ & $-1.4 \%$ & $-3.9 \%$ & $-6.4 \%$ & $-8.9 \%$ & $-8.3 \%$ \\
\hline \multirow[t]{2}{*}{ Precipitation and wind (23 Apr to 13 May) } & 0.3 & 1.1 & -1.4 & -12.5 & -22.6 & -29.1 & -36.5 \\
\hline & $0.1 \%$ & $0.5 \%$ & $-0.6 \%$ & $-5.5 \%$ & $-10.0 \%$ & $-12.8 \%$ & $-16.1 \%$ \\
\hline \multirow[t]{2}{*}{ All forcings (9-26 May) } & -1.2 & -4.8 & -22.0 & -30.7 & -49.1 & -58.1 & -49.2 \\
\hline & $-1.0 \%$ & $-3.8 \%$ & $-17.5 \%$ & $-24.4 \%$ & $-39.1 \%$ & $-46.3 \%$ & $-39.1 \%$ \\
\hline
\end{tabular}


TABLE 3. Basin-averaged SWE biases/errors on 24 April $(\overline{\mathrm{SWE}}=259 \mathrm{~mm})$, near the apex of spring melt contributions. The first number is the error and represents the cumulative model bias across the entire catchment. The number in parentheses is the MAE, which is representative of the average magnitude of errors at each $10-\mathrm{m}$ pixel. All values expressed in millimeters.

\begin{tabular}{rrrrrr}
\hline & Solar & Thermal & Wind & Precipitation/wind & All \\
\hline $30 \mathrm{~m}$ & $0.3(14.5)$ & $2.0(28.5)$ & $-0.4(7.3)$ & $-0.8(33.0)$ & $-2.6(39.8)$ \\
$100 \mathrm{~m}$ & $-0.8(23.8)$ & $5.8(48.5)$ & $-3.4(20.3)$ & $-7.5(76.6)$ & $-10.7(78.4)$ \\
$250 \mathrm{~m}$ & $-4.4(35.0)$ & $12.9(70.9)$ & $-10.9(40.7)$ & $-21.4(118.3)$ & $-29.4(109.7)$ \\
$500 \mathrm{~m}$ & $-10.5(44.6)$ & $20.5(84.9)$ & $-17.5(55.9)$ & $-35.8(143.2)$ & $-38.9(129.1)$ \\
$750 \mathrm{~m}$ & $-12.5(47.3)$ & $26.2(97.4)$ & $-23.0(64.2)$ & $-50.0(152.3)$ & $-52.1(140.3)$ \\
$1000 \mathrm{~m}$ & $-17.1(52.1)$ & $32.3(104.0)$ & $-20.4(72.0)$ & $-52.4(165.8)$ & $-47.6(152.8)$ \\
$1500 \mathrm{~m}$ & $-23.7(52.1)$ & $42.3(105.2)$ & $-23.4(69.1)$ & $-70.3(169.6)$ & $-49.1(164.5)$ \\
\hline
\end{tabular}

Though not fully visible in the figure, this $1000-\mathrm{m}$ pixel included numerous south-facing, treeless features from the southwest, windward side of the divide. The positive biases in this pixel directly correspond with the vegetation coverage. The opposite effect, negative SWI biases, occurred on canopy-free, south-facing slopes in the upper basin because of scale-induced decreases in solar radiation.

At the lower elevations, there was a reversal of the trends observed at the upper elevations-slightly negative biases on north-facing treed slopes and slightly positive biases on south-facing open slopes were present in April. Biases at the lower elevations are a response to the prior scale-induced biases. Where there had been biases toward earlier melt (e.g., in the forest stands) snow resources became depleted earlier, resulting in lower simulated SWIs later. These are the reasons for the positive-negative cycles present in Fig. 2. The first cycle corresponds to the main melt period, and the second corresponds to the melt out of the drifts. The lower elevations were predominantly snow-free by late April (Fig. 3f). The April SWI biases in Fig. 3 illustrate a catchment in transition. At the upper elevations, melt is still predominantly energy-limited, whereas the lower elevations have transitioned to a mass-limited SWI condition.

\section{b. Thermal radiation}

The responses of basin-averaged SWI to coarser model resolutions of the thermal radiation forcings were opposite in sign and greater in magnitude to those associated with the solar radiation forcings (Fig. 2b). As resolution coarsened, simulated SWI was lower throughout the winter up until the midpoint of spring snowmelt, when the corresponding positive rebound occurred. The rebound occurred later in this case as opposed to the former because of the decrease, rather than increase, of winter and early spring melt contributions (i.e., SWI). A slight bias associated with the December rain-on-snow events was evident.

Biases increased in magnitude with increasing scale. During the same 9-day period on the rising limb assessed in the solar radiation scale experiment, negative SWI biases were below $3 \%$ for the $100-\mathrm{m}$ representation increased to approximately $10 \%$ at $500-\mathrm{m}$ resolution, leveled off through the $1000-\mathrm{m}$ simulation, and increased again to almost $14 \%$ for the $1500-m$ simulation (Table 1). Positive biases on the falling limb (10-22 May) were similar in magnitude to the rising limb percentages for the 30-250-m model scales but were increasingly larger with further coarsening of model resolution (Table 2). Consistently increasing errors with decreasing model resolution across the entire season were clearly evident in Fig. $2 b$ and in the SWE errors (Table 3).

The spatial sensitivities of simulated SWI to thermal radiation scales were also greater and nearly opposite those attributable to solar radiation scaling. The MAE of the $1000-\mathrm{m}$-scaled SWE product was $104 \mathrm{~mm}$ (40\% of mean basin SWE). The April SWI deficits were due to lower contributions from the upper-elevation treed regions (Fig. 3b). The main energy inputs on these forested slopes are thermal enhancement from the overlying trees. When averaged over large pixels, incoming thermal radiation is increased over the open slopes and lessened beneath the trees. Positive/negative SWI biases are spatially concentrated in pixels containing large/ small percentages of canopy cover. At the lower elevations the "rebound" from an energy-limited system to a mass-limited system, as was seen with the solar radiation scale experiment, is again evident. The low-elevation forested areas, where greater amounts of snow were preserved because of depressed energy fluxes, now have positive SWI biases. The open slopes that had enhanced energy fluxes in the larger pixel solutions have less snow available and negative SWI biases.

\section{c. Wind}

Wind speeds affect turbulent and mass fluxes. In this analysis, the mass fluxes were kept consistent with the base 10-m simulation to isolate scale effects on simulated turbulent fluxes. In wind-affected regions, the 
a) Solar Radiation

b) Thermal Radiation

\section{c) Wind Speed}
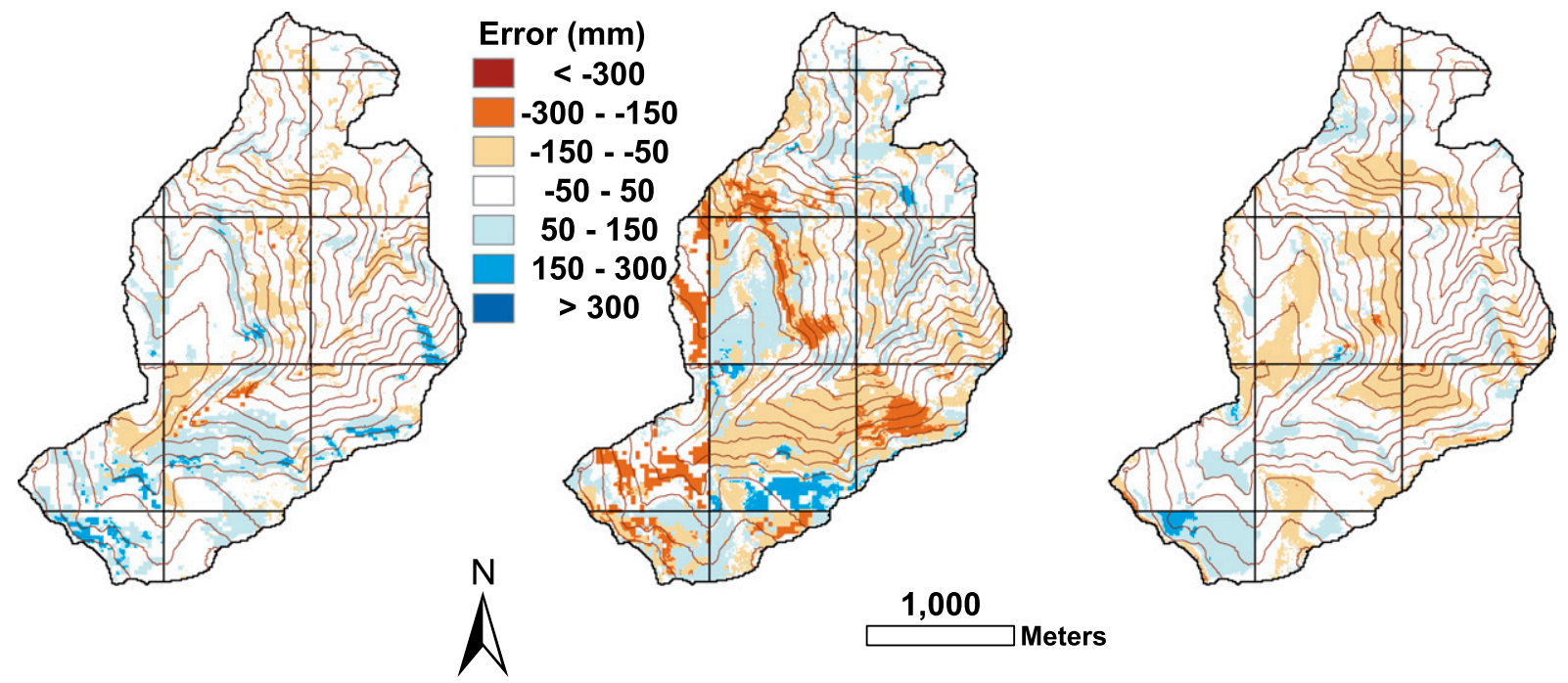

d) Precipitation and Wind

e) All Forcings
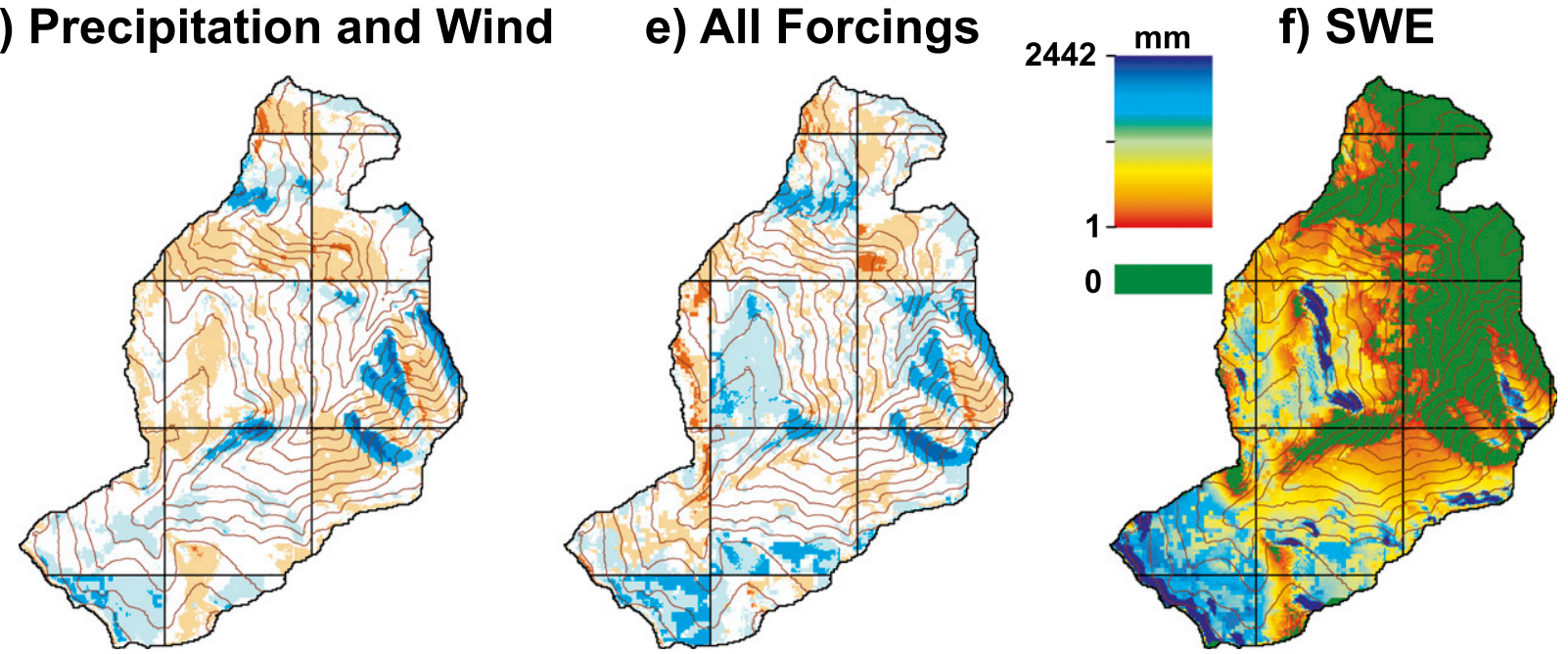

FIG. 3. (a)-(e) Distribution of April SWI errors and (f) the 10-m simulated SWE distribution on 24 April. The errors reflect the sensitivity of SWI to 1000-m model-scaled forcings for the respectively titled forcing(s). The outlined boxes are the 1000-m pixels. Errors were calculated on the 10 -m grid.

resolution of effective precipitation rates is limited by wind field resolution. However, in areas where wind has little effect on snow accumulations, precipitation rates can often be resolved with greater detail than can wind fields. This is due to the fact that wind observations are frequently sparser than precipitation observations and often fail to capture the gradient of variability. The following analysis addresses these situations. Isolation of the turbulent flux scale effects will also aid in interpreting the subsequent analysis in which wind and precipitation scalings are jointly considered.

Similar to the solar radiation scaling effect on basinwide SWI, simulated SWIs forced by coarsened wind fields were positively biased through the season until the system became mass limited (Fig. 2c). The changeover occurred slightly earlier than in the case of solar energy because of the stronger role turbulent exchanges have in affecting melt during the winter months. Model resolution did play a slight role in affecting simulated SWI during the December rain-on-snow events. Biases during the rain-on-snow events, however, were small compared to runoff magnitudes. At the basin scale, the 30-m simulation produced nearly identical results to the $10-\mathrm{m}$ solution. The $100-\mathrm{m}$ simulation was also very close to the $10-\mathrm{m}$ product. Bias and errors noticeably increased as scale increased to $750 \mathrm{~m}$. The $750-$ and $1000-\mathrm{m}$ 
simulations were nearly identical at the basin scale until errors became more pronounced at the $1000-\mathrm{m}$ resolution on the falling limb of melt production. In fact, dissimilarities in the $750-1500-\mathrm{m}$ products were small (Tables 1-3), with different configurations performing better/worse at different times in the season (Fig. 2c).

Errors on the rising limb of spring snowmelt (1316 April) were less than 5\% for the 30-250-m model scales and less than $9 \%$ for the coarser resolutions (Table 1). Similar errors were found on the falling limb (23 April to 13 May)-less than 5\% for the 30-500-m model scales and less than $9 \%$ for the coarser resolutions (Table 2). SWE biases, similar to the SWI trends, were increasingly negative as model resolution coarsened to $750 \mathrm{~m}$ and then leveled off (Table 3).

Similar to the prior analyses, distributed cumulative SWI errors in April depict energy-limited conditions at the upper elevations and mass-limited conditions at the lower elevations (Fig. 3c). In the upper basin, positive SWI biases can still be observed on wind-sheltered lee slopes and forested locations where simulated wind speeds increased with decreasing model resolution. The opposite effects were present on wind-exposed slopes. Positive biases are accentuated on the predominant lee slope in the southwestern part of the catchment. The majority of terrain covered by this particular pixel consists of wind-exposed terrain (upwind of the Dobson Creek catchment and not visible in the figure), causing a sharp increase in simulated wind speeds and earlier melt. During April, the midelevations were transitioning to a mass-limited system, whereas the lower elevations are already showing evidence of the crossover. At the lower elevations, negative biases were found on leeward slopes and positive biases were found on windward slopes.

\section{d. Precipitation and wind}

In this scenario, wind speeds and effective precipitation forcings (including wind effects on snow accumulations) were simultaneously degraded with all other forcings maintained at $10-\mathrm{m}$ resolution. These two processes were considered together based on the reasoning that wind speed resolution ultimately determines the degree to which wind-affected snow accumulations can be resolved.

It should be noted that in this scenario, precipitation mass was not conserved. The upper Dobson Creek catchment is predominantly east facing and therefore lee slopes predominate. As pixel sizes increased, pixels overlapped the westernmost catchment boundary. Lee slope drift areas in this region became subpixel features along with the windward slopes upwind of the catchment boundary. The pixel-averaged effective precipitation values were correspondingly lower, resulting in lower effective precipitation rates and SWI. This effect was more pronounced as scale increased to include increasing amounts of wind-exposed terrain in the effective precipitation calculations. These effects can be seen in the resultant negative SWI biases at the end of the simulations (Fig. 2d).

The pattern of positive SWI biases through the approximate halfway point of spring meltout followed by the consequent response toward negative biases was again evident (Fig. 2d). Throughout the winter until the onset of spring melt, the temporal traces of SWI biases for all but the 1500-m solution were nearly identical to the wind-only simulations (Fig. 2c). The 1500-m precipitation-wind simulation retained a similar shape to wind-only simulation but had slightly greater errors. Subsequent to the onset of spring melt, errors were accentuated in the wind-precipitation scenarios compared to the wind-only ones. During the energy-limited phase, SWI was more sensitive to wind scale and, as the transition to a mass-limited system took place, the scaling of the precipitation inputs took precedence.

At the basin scale, SWI biases attributable to the 30and $100-\mathrm{m}$ wind-precipitation products were very low. There was a slight loss in the ability to resolve drifts in the 100-m simulation as evidenced by the slight drop in seasonal SWI. As mentioned, biases prior to the spring melt peak were similar to the wind-only scenarios for all but the 1500-m model. Biases consistently increased with coarsening model resolution on the falling limb as modeling capabilities of resolving drift zones diminished. This can be seen in the increasingly negative end-of-season SWI biases (Fig. 2d). Though seasonal mass deficits were minor compared to seasonal inputs (e.g., $3 \%$ loss for the $1500-\mathrm{m}$ simulation), the inability to resolve the drift zones strongly affected SWI biases from late April through early June.

During a 4-day period (13-16 April) when positive biases were highest, basinwide SWI errors for the 30 500-m resolutions ranged from $0.0 \%$ to $10.1 \%$ (Table 1 ). Errors on this rising limb were $14.4 \%-18.2 \%$ for the $750-1500-\mathrm{m}$ model scales. Though there were many similarities in the basin-scaled SWI traces for the wind-only and wind-precipitation scenarios prior to spring snowmelt, rising limb SWI errors for the windprecipitation scenarios were all greater over this 4-day period. The 1000 - and $1500-\mathrm{m}$ simulations had a greater than twofold increase in errors compared to the windonly scenarios. On the falling limb (23 April to 13 May), errors were negligible for the $30-250$-m forcings $(<1.0 \%)$ and increased in magnitude as grid sizes increased beyond $250 \mathrm{~m}$ to $16.1 \%$ for the $1500-\mathrm{m}$ product (Table 2). The poor performance in late spring of the coarser 
resolutions is clearly foretold in the 24 April SWE errors (Table 3). Mean SWE errors were $-19 \%,-20 \%$, and $-27 \%$ for the $750-, 1000-$, and $1500-\mathrm{m}$ resolutions, respectively.

The main impact of the rescaling of the effective precipitation forcings was a smoothing of the snow distribution. This is apparent in the lower elevations experiencing mass-limited conditions in April. SWI inputs in April were much higher in the degraded windprecipitation scenarios than the $10-\mathrm{m}$ run on lowerelevation, wind-exposed slopes (Fig. 3e). These slopes, which typically accumulate very little snow, received greater amounts of snow as the process scale was exceeded. When energy fluxes increased in spring, more snow was available to melt. The inverse, negative SWI biases are apparent on lee slopes in the lower catchment. In April, the upper elevations were predominantly in an energy-limited stage. The high similarity in SWI biases at the upper elevations depicted in Fig. 2c (wind only) and Fig. 2d (wind-precipitation) show that in April the main scale-induced influence on SWI in this region was due to wind-scale-affected turbulent energy fluxes. Though not depicted here, the positive SWI biases on wind-exposed slopes and negative SWI biases on wind-sheltered slopes observed at the lower elevations in April were observed in May at the upper elevations when that region transitioned to a mass-limited system. Precipitation and wind-based scale effects were spatially consistent, and their combination strongly influenced simulated SWI and distributed SWE. The 24 April mean and mean absolute SWE errors were generally 2-3 times greater in the precipitation-wind scenarios than in the wind-only scenarios (Table 3 ).

When model resolution is no longer capable of resolving process-based heterogeneity, model performance is diminished. Judging from the results, there was some evidence of a loss of snowdrift information occurring at the $100-\mathrm{m}$ scale, as evidenced by the small end-of-season bias. Basin-averaged SWI errors for the 100 -m simulation, however, were very small $(<2 \%)$ throughout the peak snowmelt period. Substantial differences between the 100- and 250-m solutions, though not observed so much on the falling limb, were observed throughout the rest of the season. Mean SWE errors were $-7.5 \mathrm{~mm}$ for the $100-\mathrm{m}$ simulation and $-21.4 \mathrm{~mm}$ for the 250-m simulation. Negative SWI biases in midMay for the 250- and 500-m scaled solutions were limited (e.g., the less dramatic slopes in Fig. 2d), indicating that some drift information was maintained at these resolutions. Once the model scale extended to $750 \mathrm{~m}$ and beyond, there was little, if any, drift information remaining.

\section{e. All forcings}

In this evaluation, all of the ISNOBAL forcings-net solar radiation, downwelling thermal radiation, wind speed, effective precipitation, air temperature, vapor pressure, and soil temperature-were simultaneously degraded. In general, this is the most common situation encountered in applied modeling. As was evident in all of the prior independent process analyses except for thermal radiation, scale degradation again produced basin-averaged SWI that had a positive bias throughout the winter up until approximately the springtime peak of snowmelt-produced SWI (Fig. 2e). The positive bias noticeably increased as model scale increased through $500 \mathrm{~m}$. Differences between the 500-1500-m simulations were less pronounced and exhibited inconsistencies during the spring melt period. The inconsistencies are probably an effect of the many interacting scale-affected processes. After the peak, there was a consequent negative bias in simulated SWI due to the lack of available snow volume caused by the prior accentuated melt.

The positive biases were accentuated during the rainon-snow events in late December and again during the onset of the spring melt period. Large differences were observed between the 100-, 250-, and 500-m simulations. During a 4-day period on the rising limb of spring melt (13-16 April, the same as evaluated in the precipitation and wind scenarios), there was only a $3.3 \%$ bias for the $100-\mathrm{m}$ simulation, which rose to $11.7 \%$ for the $250-\mathrm{m}$ simulation and $18.4 \%$ for the $500-\mathrm{m}$ simulation (Table 1 ). Errors were all in the $20 \%$ range for the $500-1500-\mathrm{m}$ simulations. During an 18-day period on the falling spring snowmelt limb (9-26 May), the biases had greater magnitudes with SWI shortages near $40 \%$ for the 750 - and $1500-\mathrm{m}$ simulations and over $45 \%$ for the $1000-\mathrm{m}$ simulation (Table 2). The 100-m simulation remained within $4 \%$ of the 10-m simulation while the 250- and 500-m simulations had respective differences of $17.5 \%$ and $24.4 \%$. Distributed SWE errors were expectantly high, yet comparable to and sometimes less than the precipitationwind scenarios (Table 3). The 24 April SWE errors are comparable because of the offsetting effects of the degraded thermal (less winter melt), solar (more), and wind (more) forcings during the preceding period. As the solar fluxes started to dominate the radiation balance, scale-induced radiation effects reinforce the precipitationwind biases and errors increased in magnitude throughout the spring in the all-forcings scenarios.

The positive SWI biases in April were concentrated on wind-exposed, treeless slopes in the lower basin and on the lee slopes at the head of the catchment (Fig. 3e). On wind-exposed slopes, coarsening model resolutions caused simulated snow accumulations to increase, wind 
speeds to decrease, and thermal radiation to increase when tree stands were also present in the pixel. The effect of the increased snow accumulations can be readily seen in the mass-limited conditions at the lower elevations. The only complete 1000 -m pixel depicted in Fig. 3e shows these effects just starting to influence SWI higher up in the basin. In the energy-limited environment at the upper elevations, increased thermal fluxes on open slopes and increased turbulent fluxes on lee slopes produced positively biased SWI. Negative SWI biases in April occurred in directly contrasting conditions but were not as widespread. Low-elevation lee slopes had negative biases due to scale-induced decreases in snow accumulations while canopy stands at the higher elevations had negative biases due to scaleinduced decreases in downwelling thermal radiation. Comparisons of Figs. 3a-e provide interesting insights into the complexities of how the scale-affected controlling processes ultimately affected snowmelt patterns.

\section{Discussion}

Prevailing winds during storms in this catchment, as they are throughout most of the western United States, are out of the southwest. These winds accentuate snow deposition on north-facing, solar-shaded slopes while reducing accumulations on south-facing, solar-exposed slopes. This establishes a snow environment where accumulations and energy fluxes are negatively correlated. Snow preferentially accumulates on slopes with low net energy inputs while less snow accumulates on slopes with high net energy inputs. The latter areas have a greater likelihood of producing melt throughout the winter and early spring. Relatively warmer snowpacks, susceptible to producing melt in response to additional energy inputs, are also present beneath the forest canopy. There, the additional thermal radiation emitted by the forest canopy effectively constrains nighttime radiational cooling.

Model performance was most sensitive to the model scale of the effective precipitation inputs. The scaleinduced smoothing put more snow on slopes with high energy fluxes and less snow in low-energy zones. Clow et al. (2012) came to similar conclusions that SNODAS, a $1000-\mathrm{m}$ grid scale model developed by the U.S. National Weather Service, had difficulties simulating SWE on wind-affected slopes. The smoothed mass fluxes led to earlier simulated melt and a higher spring snowmelt peak. The scale-induced reduction of snow in enhanced accumulation zones led to reductions in simulated SWE and SWI after the spring snowmelt peak. While scaleinduced smoothing of the energy inputs produced both earlier (e.g., solar radiation and turbulent fluxes) and later melt (e.g., thermal radiation), the net effect of increasing model scales was dominated by precipitation distributions which shifted the system toward earlier melt. The shifts toward earlier melt were due to the negative correlation of mass and energy fluxes. In regions with similar accumulation heterogeneities and positively correlated mass and energy fluxes, scale-induced smoothing would be expected to delay snowmelt as greater mass is shifted into low-energy areas. In regions with lower accumulation heterogeneities, shifts might not be as straightforward as scale-induced biases attributable to the energy fluxes become more prominent.

Semivariogram analyses were conducted to assess 1) how the modeled snow variability and scale behavior in this study compared to observations from other mountain sites and 2) if the observed sensitivities to forcing data resolution could be related to physiographic properties. The latter assessment provides a foundation for the results presented here and as a potential guide for making a priori scaling decisions in other catchments. The presented analysis is akin to, but less extensive than, that presented by Deems et al. (2006). Omnidirectional $\log -\log$ semivariogram plots were evaluated to broadly estimate scale breaks and fractal dimensions $D$. Following the protocols laid out in Deems et al. (2006), nonstationarity in the data was not removed and logwidth bins were used to improve definition of scale behavior at short lag distances. Scale breaks, indicative of distinct changes in process behavior and its spatial organization, were identified by visual disparities in the linear (power law) response of semivariance to scale. Where appropriate for interstudy comparisons, $D$ was estimated from the slope of the linear segments $(D=3-$ $b / 2$, where $b$ is the slope). In this three-dimensional space, $D$ will vary between 2 (an unvarying flat surface) and 3 (completely random, highly heterogenic structure).

The semivariogram for modeled SWE at upper Dobson Creek on 18 March is depicted in Fig. 4a. This date was selected because it had the maximum basinwide SWE prior to the onset of spring melt with $99 \%$ of the catchment area snow covered. The presented analysis covers lag distances of up to $1200 \mathrm{~m}$ (117 bins) approximately half of the maximum cross-stream width of the basin-to concentrate on the scale issues relevant to the already presented findings. A scale break, indicated by the break in power-law fits (the linear segments in the log-log plot) between 50 and $100 \mathrm{~m}$ was inferred from this plot with a short-range $D$ of 2.55 and a long-range $D$ of 2.88 (Fig. 4a). Deems et al. (2006) and Trujillo et al. (2007) respectively determined scale breaks from high-resolution lidar snow-depth data of $15-40 \mathrm{~m}$ and $7-45 \mathrm{~m}$ at several $1 \mathrm{~km}^{2}$ Colorado research sites. The longer scale break found in this study is 
a) Modeled 10m SWE

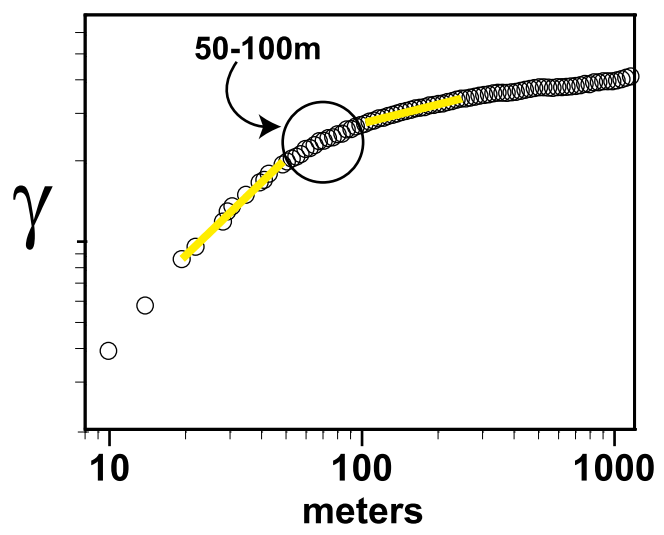

c) Vegetation Heights

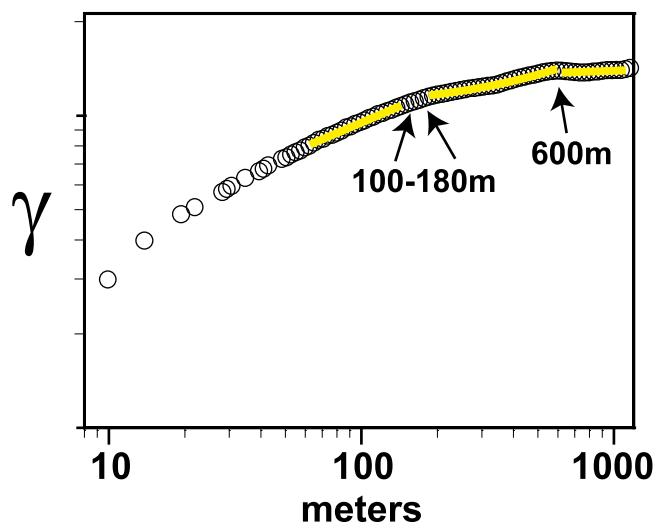

b) $S x$

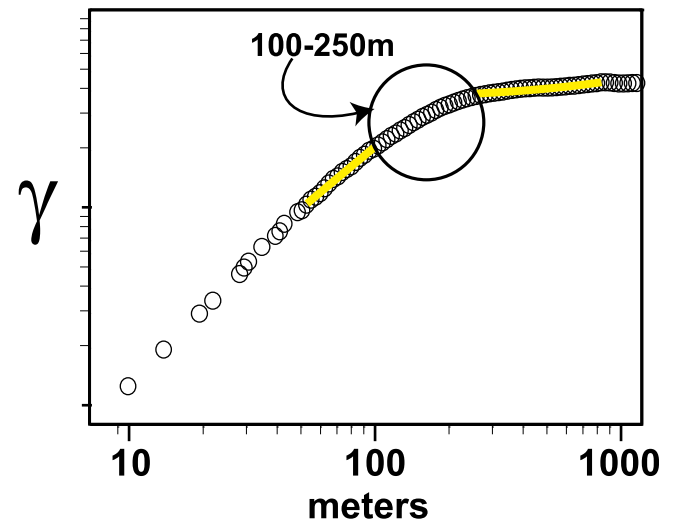

d) April Solar Loadings

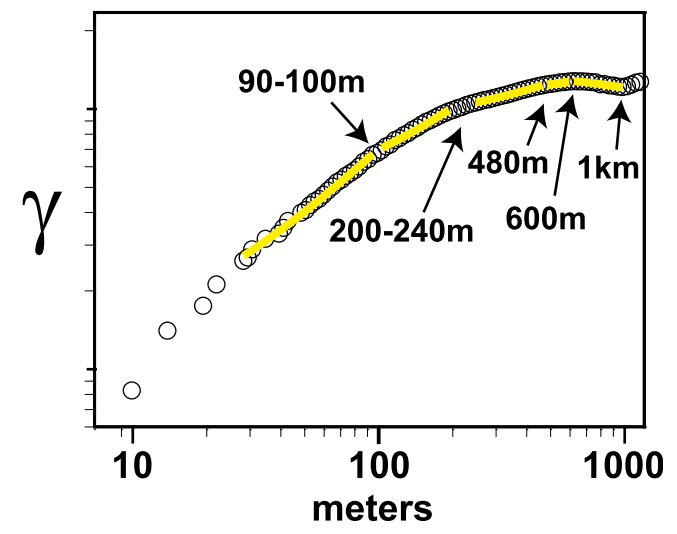

FIG. 4. (a) Log-log semivariograms for ISNOBAL-simulated SWE on 24 April, (b) the Sx terrain parameter focused on the prevailing wind direction of $235^{\circ}$, (c) canopy heights derived from lidar point clouds, and (d) cumulative modeled April net radiation fluxes to the snowpack. Lines are linear least squares fits to visually delineated segments.

indicative of similarities existing over greater distances. This observation, however, may in fact be related to the differences in the spacing of observations (10-m model elements and nominal 1.5-m lidar spacing) rather than differences in the snow distributions. There is insufficient data in the $10-\mathrm{m}$ product to adequately resolve scale breaks of less than $30 \mathrm{~m}$ (e.g., Fassnacht and Deems 2006). Snow-depth fractal dimensions approximated by Deems et al. (2006) varied between 2.47 and 2.48 for the short-range $D$ (i.e., shorter than the scale break) and between 2.91 and 2.97 for the long-range $D$ (i.e., longer than the scale break). Given similar snow distributions and similarly scaled observations, fractal dimensions for SWE, however, should be lower than depth fractal dimensions because of the greater spatial coherence of snow density (Elder et al. 1991). The higher short-range $D$ found in this analysis of SWE might also be related to the differing observation scales.
While these direct quantitative comparisons are obviously affected by the differing observation scales, it can still be generally stated that the scaling characteristics of the modeled snow distribution are comparable to observations from similar wind-affected sites.

There were considerable shifts in simulated SWI and SWE observed across varying scales for the analyzed processes in the presented results. As process resolution coarsened, the earliest notable upticks in SWI and SWE errors are the most likely points where model and process scales first became mismatched. Precipitation, wind, and thermal radiation displayed substantial upticks in errors and biases between the 100- and 250-m solutions, as did the all-forcings scenario. SWI and SWE sensitivity to solar radiation model scales escalated between the 250- and 500-m solutions, with some differences between the 100- and 250-m solutions becoming apparent after the spring melt peak. Precipitation and wind 
forcings were both dependent on the Sx terrain variable (Winstral et al. 2009, 2013). The semivariogram for Sx derived for the prevailing wind direction of $235^{\circ}$ indicated a scale break between 100 and $250 \mathrm{~m}$ (Fig. 4b). This break directly corresponds to the model-determined scale break for wind but was slightly greater than the model-determined SWE scale break. Whereas winds are $100 \%$ reliant on the Sx variable, effective precipitation is also influenced by the Sb terrain variable (Winstral et al. 2013). The variable $\mathrm{Sb}$ is a binary variable that delineates drift regions that highly influenced the effective precipitation distributions in this catchment. A better, though more comprehensive, means of delineating the modelbased break in SWE distribution would be an analysis of the cumulative precipitation forcings. These latter data, however, are not available a priori. Prior distributions can be an effective tool when snow distributions exhibit interannual consistency (e.g., Deems et al. 2008), but may be prone to errors when distributions exhibit nonstationarity (e.g., Pomeroy et al. 2006).

A semivariogram of tree heights was constructed from recently acquired lidar data (Fig. 4c) coarsened to $10 \mathrm{~m}$ to match the base model scale. The initial scale break appears to occur between 100 and $180 \mathrm{~m}$. A more distinct break can be seen at approximately $600 \mathrm{~m}$. Model sensitivity to scaling of the thermal radiation inputs, which are heavily influenced by canopy cover, similarly exhibited a break in scaling behavior between 100 and $250 \mathrm{~m}$. No particular changes in model behavior were evident around the larger-scale break. In the case of solar scaling, semivariograms of northness and cumulative solar loadings were analyzed. The first break in scale for northness occurred around $500 \mathrm{~m}$ (not shown), whereas the modeling sensitivity indicated potential breaks between 100,250 , and $500 \mathrm{~m}$. The semivariogram of cumulative solar loadings through 1 April (Fig. 4d) did exhibit a scale break between 200 and $240 \mathrm{~m}$ commensurate with the modeling results. The solar loadings also had scale breaks at 600 (probably associated with the vegetation distribution) and $1000 \mathrm{~m}$. Breaks at 95 and $480 \mathrm{~m}$ were apparent, but not as clear cut. The occurrence of numerous scale breaks is most likely due to the various factors (e.g., canopy cover, terrain, sun angle, and cloudiness) and their stochastic interactions that ultimately control solar radiation fluxes.

One conclusion that can be drawn from this work is that if a single model scale were chosen to best predict basin runoff in this catchment while conserving computation times, it would be $100 \mathrm{~m}$. Though it was shown that SWE distributions were compromised at this resolution, there was very little change in the timing and magnitudes of SWI production. This was due to the fact that both positive and negative SWE errors occurred in close proximity to one other. Whereas the SWE distribution on 24 April had an MAE of $78.4 \mathrm{~mm}$ in the $100-\mathrm{m}$ all-process model run, MAE was reduced by over $75 \%$ to $18.6 \mathrm{~mm}$ when all errors within $100 \mathrm{~m}$ of each $10-\mathrm{m}$ pixel were averaged. The proximity of surpluses and deficits indicates that these SWE errors probably occurred in zones with similar energy fluxes and stream connectivity that limited effects on basin runoff. In regions with more or less complex snow and vegetation distributions, further analysis would be required before selecting an appropriate and optimal model scale.

Based on the prior results, models with varying scales were designed in an effort to further reduce computational costs from the all-forcings 100-m simulation. Since all of the process sensitivities had substantial accuracy losses when model resolution was increased from 100 to $250 \mathrm{~m}$ during the spring snowmelt period, the effort was focused on the effects of degraded winter model resolutions. Effective precipitation and associated wind speeds and vapor pressures that were used to determine precipitation type (Marks et al. 2013) and thus windaffected snow accumulations were kept at $100-\mathrm{m}$ resolution throughout the season. Radiation fluxes were modeled with 250-, 500-, and 1000-m resolution through 1 March. After 1 March, all forcing model resolutions were set to $100 \mathrm{~m}$ to best capture energy fluxes during the spring melt period. These three scenarios are respectively labeled $250 \mathrm{~m} / 100 \mathrm{~m}$ (winter/spring resolutions), $500 \mathrm{~m} / 100 \mathrm{~m}$, and $1000 \mathrm{~m} / 100 \mathrm{~m}$ in the associated figures and table.

In terms of basin-averaged SWI, the 250- (labeled $250 \mathrm{~m} / 100 \mathrm{~m}$ in Fig. 5) and 500-m (labeled $500 \mathrm{~m} / 100 \mathrm{~m}$ ) winter model resolutions actually outperformed the 100 -m (labeled $100 \mathrm{~m} / 100 \mathrm{~m}$ ) simulation during the winter but had slightly higher spring SWI on the rising limb. Rising limb (4 April to 11 May) cumulative SWI for the $250-\mathrm{m}$ winter simulation was only $0.5 \mathrm{~mm}$ greater than the 100-m all-forcings SWI (cumulative SWI during period was $377 \mathrm{~mm}$ ), while the $500-\mathrm{m}$ winter simulation was $1.3 \mathrm{~mm}$ higher and the $1000-\mathrm{m}$ winter (labeled $1000 \mathrm{~m} / 100 \mathrm{~m}$ ) was $10.0 \mathrm{~mm}$ higher (Table 4). Basinaveraged SWI in the 1000 -m winter simulation was biased toward later melt through the winter leading to the greater rising limb SWI errors. All three models were heavily influenced by the scale of the thermal radiation forcings. Winter SWI production had greater sensitivity to the scaling of thermal radiation inputs than to that of solar radiation forcings (Figs. 2a,b). Negative biases associated with the 250- and 500-m scaled thermal radiation compensated for scale-induced positive biases associated with all the other processes. At $1000 \mathrm{~m}$ the increasingly negative thermal bias became the dominant flux. Though basin-averaged SWE and SWI errors were 


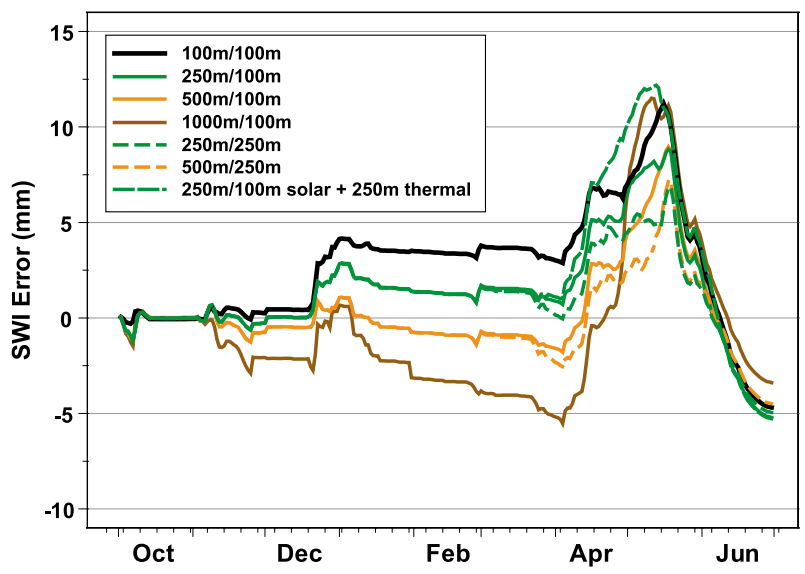

FIG. 5. Cumulative SWI error plots for the optimized, variously scaled radiation forcings. The numbers before the slash represent grid resolutions for the solar and thermal radiation forcings prior to $1 \mathrm{March}$; the numbers after the slash represent the radiation forcings for the subsequent period. The $100 \mathrm{~m} / 100 \mathrm{~m}$ plot is repeated from Fig. 2 for comparative purposes. The 250-m all-season solar and thermal fluxes actually reduced SWI errors compared to the $100-\mathrm{m}$ all-season and $250 \mathrm{~m} / 100 \mathrm{~m}$ scenarios and were much better than the combined $250 \mathrm{~m} / 100 \mathrm{~m}$ solar $+250 \mathrm{~m}$ thermal simulation. As model scale increased beyond the process scale for the thermal fluxes, negative SWI biases increased, which compensated for the positive errors introduced by increased model scaling of the solar radiation flux.

improved with the 250- and 500-m winter forcings, distributed SWE errors on 24 April increased (Table 4). Compared to the 100-m all-forcings simulation, all SWE MAEs for the rescaled winter forcings increased. These increases however, were all less than $15 \mathrm{~mm}$.

The 250- and 500-m winter forcings were retained in the following scenarios. Instead of 100-m springtime radiation fluxes, this time $250-\mathrm{m}$ forcings were used (labeled 250/250 and 500/250, respectively, in Fig. 5). In both these latter cases, basin-averaged SWI performed slightly better, but SWE errors slightly increased (Table 4; Fig. 5). The next step was to pair the 250-m winter forcings with $250-\mathrm{m}$ solar radiation fluxes and $100-\mathrm{m}$ thermal radiation fluxes after 1 March to isolate the solar influences on snowmelt (labeled 250/100 m solar + $250 \mathrm{~m}$ thermal). The higher-resolution springtime solar forcings $(100 \mathrm{~m})$ actually decreased model performance on the rising limb compared to the 250 -m resolution solar forcings (Fig. 5), despite the fact that the latter introduced greater bias in the earlier sensitivity analysis (Fig. 2a; Tables 2, 3). The degradation of the representation of solar fluxes, however, can be masked at the basin scale by similar degradation of processes that introduce a compensating bias. This points out the importance of acutely assessing scale-related biases and impacts before broad-scaled assumptions are made.
TABLE 4. Rising limb SWI (4 Apr to 11 May) and SWE (24 Apr) errors for the optimized simulations (roman) with reference to the earlier presented $100-$ and $250-\mathrm{m}$ all-forcings simulations (italicized). In the optimized versions, only the winter (before 1 Mar) and spring (after 1 Mar) thermal and solar radiation scales were adjusted as outlined in the first column.

\begin{tabular}{crcr}
\hline $\begin{array}{c}\text { Winter/spring radiation } \\
\text { resolutions }\end{array}$ & $\begin{array}{c}\text { SWI error } \\
(\mathrm{mm})\end{array}$ & $\begin{array}{c}\text { SWE error } \\
(\mathrm{mm})\end{array}$ & $\begin{array}{c}\text { SWE MAE } \\
(\mathrm{mm})\end{array}$ \\
\hline $100 \mathrm{~m} / 100 \mathrm{~m}$ & 6.8 & -10.7 & 78.4 \\
$250 \mathrm{~m} / 250 \mathrm{~m}$ & 20.7 & -29.4 & 109.7 \\
$250 \mathrm{~m} / 100 \mathrm{~m}$ & 7.3 & -9.7 & 87.5 \\
$250 \mathrm{~m} / 250 \mathrm{~m}$ & 5.1 & -9.2 & 94.7 \\
$250 \mathrm{~m} / 100 \mathrm{~m}$ solar $+250 \mathrm{~m}$ & 11.0 & -13.1 & 84.1 \\
thermal & & & \\
$500 \mathrm{~m} / 100 \mathrm{~m}$ & 8.1 & -6.7 & 92.7 \\
$500 \mathrm{~m} / 250 \mathrm{~m}$ & 6.0 & -6.2 & 99.3 \\
$1000 \mathrm{~m} / 100 \mathrm{~m}$ & 16.8 & -3.4 & 92.1 \\
\hline
\end{tabular}

Computational savings can be garnered through the winter; however, prudence is advised in using model scales greater than $100 \mathrm{~m}$ for any of the forcing processes during the spring melt period in catchments such as these.

Before concluding this work, it is important to make several points. All of the rescaling in this work was based on an averaging of $10-\mathrm{m}$ pixels. As a result, there was some retention of information from the higherresolution solutions within the rescaled products. Scaleinduced biases and errors would in all likelihood be greater when starting with lower-resolution data such as a 100-m DEM. Snow interception losses, an important control on snow accumulations in many other environments, were not addressed in this study. The sensitivities to air temperature were also not directly addressed. Rescaling of air temperatures would have necessitated recalculating thermal radiation fluxes and precipitation phase at every rescaling step, which was not possible within the time constraints of this project. Air temperatures rescaled independently of their effect on thermal radiation fluxes and precipitation phase were shown to have very little effect on runoff production in a more extensive analysis conducted in this basin (Winstral 2011). In that study, it was shown that during spring snowmelt large grid cells containing a large range of elevations were biased toward lower melt at the lower elevations and higher melt at the upper elevations. This could be a larger issue at the even larger grid resolutions associated with regional- and continental-scale modeling. This analysis was conducted over a relatively small, first-order watershed where snow distribution and melt fluxes are highly heterogeneous and strongly connected to runoff. While these characteristics are often encountered throughout the Great Basin region of the western 
United States, vastly different environments will in all likelihood exhibit dissimilar characteristics. The relative impacts of the process-based model scales on catchmentwide snowmelt and streamflow are also likely to be different when evaluated over larger domains.

\section{Conclusions}

Mismatched model and process scales had a pronounced impact on distributed mass- and energy-balance snow simulations. At this study site, where mass and energy fluxes are negatively correlated, there was an overall trend toward earlier melt when model resolution exceeded process-scale heterogeneity. As increasing pixel sizes further smoothed natural heterogeneities, the dominant effect was greater amounts of snow in high-energy zones, less snow in low-energy zones, and consequent earlier melt and late season water deficits. Simulations run with all processes modeled at $30 \mathrm{~m}$ were nearly identical to 10-m realizations. Though there was some loss of accuracy at $100-\mathrm{m}$ resolution, the simulations maintained the hydrologically relevant features of the SWE distribution with errors on the rising and falling limb of the spring snowmelt period less than 4\% MAE. As model scale increased to $250-\mathrm{m}$ and larger, errors increased. The 1000-m simulation overpredicted the rising limb by $19 \%$ and underpredicted the falling limb by $46 \%$.

The sensitivity of snow simulations to the resolution of the primary forcing processes affecting accumulation and melt in this basin-wind-affected snow accumulations, wind speeds, solar radiation, and thermal radiationvaried by process and time of year. These are important considerations for designing models, interpreting results when scale mismatches are unavoidable, and for reducing computational costs. Model scales for the dominant controls on accumulation in this basin-wind and effective precipitation-needed to be maintained at $100 \mathrm{~m}$ to preserve hydrologically relevant features. Snow simulations were less sensitive to the scaling of the solar (scale-biased toward earlier melt) and thermal (scale-biased toward later melt) forcings especially through the winter. The radiation fluxes could be further degraded through the winter months (OctoberMarch) with only minor effects on accumulation and melt patterns. During the spring melt period simulations forced with $100-\mathrm{m}$ grid resolutions across all forcings were consistent with the 10 -m product with daily volumes estimated to within $4 \%$. It was shown that further coarsening of model resolution, beyond which process representations were shown to degrade, could actually improve basin-averaged simulations as thermal and solar radiation biases balanced one another. This highlights the importance of rigorously assessing scale-related biases and impacts in all complex, physically based model applications. Process-level inadequacies can be masked in broader analyses. Furthermore, biases and errors can have spatiotemporal tendencies such that the findings presented here may not apply in different environments.

The model-based sensitivities to scale are likely related in some degree to physiographic and vegetative structures. These relationships could facilitate modeling choices in other regions. The distribution of a terrain variable used in the wind distributions captured the model-discerned scale break associated with the wind forcings. Canopy structure, because of its patchy distribution, has a strong influence on the radiation budget. A semivariogram of tree heights pointed out a scale break at the same lag distance observed in the thermal radiation scaling analysis. A priori discernment of the effective precipitation and solar scale breaks proved a little more difficult. A priori scale decisions for these latter processes could come from snow observations and modeling solutions.

This work illuminates many details of the underlying sensitivities of model performance to the commonly applied model scales associated with small watershed to river basin hydrologic modeling-scales imposed by available data sources and computational requirements. It was found that though some analyses were straightforward, the complex and dynamic nature of process interactions that affect snow distribution and melt can also lead to improved results for the wrong reasons. This was a complex analysis of processes and scales in one small catchment. Future work will assess scale dependencies in other environments. There are several questions to be answered: 1) How are observed scale breaks related to topographic gradients?; 2) How are observed scale breaks related to vegetation structure?; and 3) How are observed scale breaks related to the dominant controls on accumulation and melt? In regards to snow distributions, there have been both similar observations on the effect of topographic gradients (Deems et al. 2006; Shook and Gray 1996) and dissimilar observations on the role of vegetation and topography (Deems et al. 2006; Trujillo et al. 2007). Another important aspect is to ascertain the importance of these process-based scale assessments in larger regional to continental models. Future work will look at these issues from a modeling perspective to further guide model applications and interpretation across a wide range of environments.

Acknowledgments. We thank Dr. Jeffrey Deems and two anonymous reviewers for their very insightful comments and suggestions. The data and analysis presented in this paper were funded in part by USDA-ARS CRIS Understanding Snow and Hydrologic Processes 
in Mountainous Terrain with a Changing Climate (536213610-008-00D), USDA-ARS Headquarters Student Career Experience Program (SCEP), USDA-NRCS Conservation Effects Assessment Project (5352-136100-00914R), USDA-NRCS Water and Climate Center-Portland, OR (5362-13610-008-03R), NSF-CBET(0854553), NSFMRI (EAR-1126887), and NSF Idaho EPSCoR Program (EPS-0814387). Any reference to specific equipment types or manufacturers is for information purposes and does not represent a product endorsement or recommendation. USDA is an equal opportunity provider and employer.

\section{REFERENCES}

Anderson, E. A., 1976: A point energy and mass balance model of a snow cover. NOAA Tech. Rep. NWS 19, 150 pp. [Available online at http://amazon.nws.noaa.gov/articles/HRL_Pubs_ PDF_May12_2009/HRL_PUBS_51-100/81_A_POINT_ENERGY_ AND_MASS.pdf.]

Barrett, A., 2003: National Operational Hydrologic Remote Sensing Center Snow Data Assimilation System (SNODAS) products at NSIDC. NSIDC Special Rep. 11, 19 pp. [Available online at https://nsidc.org/pubs/documents/special/nsidc_special_ report_11.pdf.]

Blöschl, G., 1999: Scaling issues in snow hydrology. Hydrol. Processes, 13, 2149-2175, doi:10.1002/(SICI)1099-1085(199910)13: 14/15<2149::AID-HYP847>3.0.CO;2-8.

Bowman, W. D., 1992: Inputs and storage of nitrogen in winter snowpack in an alpine ecosystem. Arct. Alp. Res., 24, 211-215, doi:10.2307/1551659.

Brooks, P. D., and M. W. Williams, 1999: Snowpack controls on nitrogen cycling and export in seasonally snowcovered catchments. Hydrol. Processes, 13, 2177-2190, doi:10.1002/(SICI)1099-1085(199910)13:14/15<2177:: AID-HYP850>3.0.CO;2-V.

Carroll, T., D. Cline, G. Fall, L. Nilsson, L. Li, and A. Rost, 2001: NOHRSC operations and the simulation of snow cover properties for the conterminous U.S. Proc. 69th Annual Meeting of the Western Snow Conf., Sun Valley, ID, Western Snow Conference, 14 pp. [Available online at www. westernsnowconference.org/sites/westernsnowconference.org/ PDFs/2001Carroll.pdf.]

Cline, D., K. Elder, and R. Bales, 1998: Scale effects in a distributed snow water equivalence and snowmelt model for mountain basins. Hydrol. Processes, 12, 1527-1536, doi:10.1002/ (SICI)1099-1085(199808/09)12:10/11<1527::AID-HYP678>3.0.CO;2-E.

Clow, D. W., L. Nanus, K. L. Verdin, and J. Schmidt, 2012: Evaluation of SNODAS snow depth and snow water equivalent estimates for the Colorado Rocky Mountains, USA. Hydrol. Processes, 26, 2583-2591, doi:10.1002/hyp.9385.

Deems, J. S., S. R. Fassnacht, and K. J. Elder, 2006: Fractal distribution of snow depth from LiDAR data. J. Hydrometeor., 7, 285-297, doi:10.1175/JHM487.1.

,-- , and -2008 : Interannual consistency in fractal snow depth patterns at two Colorado mountain sites. J. Hydrometeor., 9, 977-988, doi:10.1175/2008JHM901.1.

Dozier, J., 1980: A clear-sky spectral solar radiation model for snow-covered mountainous terrain. Water Resour. Res., 16, 709-718, doi:10.1029/WR016i004p00709.
_ , and J. Frew, 1981: Atmospheric corrections to satellite radiometric data over rugged terrain. Remote Sens. Environ., 11, 191-205, doi:10.1016/0034-4257(81)90019-5.

Dressler, K. A., S. R. Fassnacht, and R. C. Bales, 2006: A comparison of snow telemetry and snow course measurements in the Colorado River basin. J. Hydrometeor., 7, 705-712, doi:10.1175/JHM506.1.

Dubayah, R., 1994: Modeling a solar radiation topoclimatology for the Rio Grande River basin. J. Veg. Sci., 5, 627-640, doi: $10.2307 / 3235879$.

Elder, K., J. Dozier, and J. Michaelsen, 1991: Snow accumulation and distribution in an alpine watershed. Water Resour. Res., 27, 1541-1552, doi:10.1029/91WR00506.

Fassnacht, S. R., and J. S. Deems, 2006: Measurement sampling and scaling for deep montane snow depth data. Hydrol. Processes, 20, 829-838, doi:10.1002/hyp.6119.

Garen, D. C., and D. Marks, 2005: Spatially distributed energy balance snowmelt modelling in a mountainous river basin: Estimation of meteorological inputs and verification of model results. $J$. Hydrol., 315, 126-153, doi:10.1016/j.jhydrol.2005.03.026.

Hanson, C. L., F. B. Pierson, and G. L. Johnson, 2004: Dualgauge system for measuring precipitation: Historical development and use. J. Hydrol. Eng., 9, 350-359, doi:10.1061/ (ASCE)1084-0699(2004)9:5(350).

Hardy, J. P., R. Melloh, P. Robinson, and R. Jordan, 2000 Incorporating effects of forest litter in a snow process model. Hydrol. Processes, 14, 3227-3237, doi:10.1002/ 1099-1085(20001230)14:18<3227::AID-HYP198>3.0.CO;2-4.

Ishikawa, M., 2003: Spatial mountain permafrost modelling in the Daisetsu Mountains, northern Japan. Permafrost: Proceedings of the Eighth International Conference on Permafrost, M. Phillips, S. M. Springman, and L. U. Arenson, Eds., A. A. Balkeman, 473-478.

Jones, H. G., 1999: The ecology of snow-covered systems: A brief overview of nutrient cycling and life in the cold. Hydrol. Processes, 13, 2135-2147, doi:10.1002/(SICI)1099-1085(199910)13: 14/15<2135::AID-HYP862>3.0.CO;2-Y.

Kuchment, L. S., and A. N. Gelfan, 2001: Statistical self-similarity of spatial variations of snow cover: Verification of the hypothesis and application in the snowmelt runoff generation models. Hydrol. Processes, 15, 3343-3355, doi:10.1002/ hyp.1032.

Kumar, M., D. Marks, J. Dozier, M. L. Reba, and A. Winstral, 2013: Evaluation of distributed hydrologic impacts of temperatureindex and energy-based snow models. Adv. Water Resour., 56, 77-89, doi:10.1016/j.advwatres.2013.03.006.

Ling, C.-H., E. G. Josberger, and A. S. Thorndike, 1995: Mesoscale variability of the upper Colorado River snowpack. Nord. Hydrol., 27, 312-322.

Link, T. E., and D. Marks, 1999: Point simulation of seasonal snow cover dynamics beneath boreal forest canopies. J. Geophys. Res., 104, 27 841-27 857, doi:10.1029/1998JD200121.

Luce, C. H., D. G. Tarboton, and K. R. Cooley, 1998: The influence of the spatial distribution of snow on basinaveraged snowmelt. Hydrol. Processes, 12, 1671-1683, doi:10.1002/(SICI)1099-1085(199808/09)12:10/11<1671:: AID-HYP688>3.0.CO;2-N.

Marks, D., and J. Dozier, 1979: A clear-sky longwave radiation model for remote alpine areas. Arch. Meteor. Geophys. Bioklimatol. Ser. B, 27, 159-187.

- J. Domingo, and J. Frew, 1999a: Software tools for hydroclimatic modeling and analysis: Image Processing Workbench, ARS-USGS version 2. ARS Tech. Bulletin 99-1, Northwest 
Watershed Research Center, Agricultural Research Service, USDA, Boise, ID. [Available online at http://cgiss.boisestate. edu/ hpm/software/IPW/index.html.]

- - — D. Susong, T. Link, and D. Garen, 1999b: A spatially distributed energy balance snowmelt model for application in mountain basins. Hydrol. Processes, 13, 1935-1959, doi:10.1002/ (SICI)1099-1085(199909)13:12/13<1935::AID-HYP868>3.0.CO;2-C.

- A. Winstral, M. L. Reba, J. W. Pomeroy, and M. Kumar, 2013: An evaluation of methods for determining during-storm surface precipitation phase and the rain/snow transition elevation at the surface in a mountain basin. Adv. Water Resour. 55, 98-110, doi:10.1016/j.advwatres.2012.11.012.

Marshall, S. E., and S. G. Warren, 1987: Parameterization of snow albedo for climate models. IAHS Publ., 166, 43-50. [Available online at http://iahs.info/uploads/dms/iahs_166_0043.pdf.]

Melloh, R. A., J. P. Hardy, R. E. Davis, and P. B. Robinson, 2001: Spectral albedo/reflectance of littered forest snow during the melt season. Hydrol. Processes, 15, 3409-3422, doi:10.1002/hyp.1043.

Pohl, S., P. Marsh, and G. E. Liston, 2006: Spatial-temporal variability in turbulent fluxes during spring snowmelt. Arct. Antarct. Alp. Res., 38, 136-146, doi:10.1657/1523-0430(2006)038[0136: SVITFD]2.0.CO;2.

Pomeroy, J. W., and D. M. Gray, Eds., 1995: Snowcover: Accumulation, Relocation and Management. Environment Canada, 144 pp.

— cesses, 20, 923-941, doi:10.1002/hyp.6124.

Prasad, R., D. G. Tarboton, G. E. Liston, C. H. Luce, and M. S. Seyfried, 2001: Testing a blowing snow model against distributed snow measurements at Upper Sheep Creek, Idaho, United States of America. Water Resour. Res., 37, 1341-1350, doi:10.1029/2000WR900317.

Prowse, T. D., and I. F. Owens, 1982: Energy balance over melting snow, Craigieburn Range, New Zealand. J. Hydrol. N. Z., 21 (2), 133-147.
Seyfried, S., L. E. Grant, D. Marks, A. Winstral, and J. McNamara, 2009: Simulated soil water storage effects on streamflow generation in a mountainous snowmelt environment, Idaho, USA. Hydrol. Processes, 23, 858-873, doi:10.1002/hyp.7211.

Shook, K., and D. M. Gray, 1996: Small-scale spatial structure of shallow snowcovers. Hydrol. Processes, 10, 1283 1292, doi:10.1002/(SICI)1099-1085(199610)10:10<1283:: AID-HYP460>3.0.CO;2-M.

Trujillo, E., J. A. Ramírez, and K. J. Elder, 2007: Topographic, meteorologic, and canopy controls on the scaling characteristics of the spatial distribution of snow depth fields. Water Resour. Res., 43, W07409, doi:10.1029/2006WR005317.

Warren, S. G., and W. J. Wiscombe, 1980: A model for the spectral albedo of snow. II: Snow containing atmospheric aerosols. J. Atmos. Sci., 37, 2734-2745, doi:10.1175/1520-0469(1980)037<2734: AMFTSA $>2.0 . \mathrm{CO} ; 2$

Winstral, A., 2011: Spatial scaling of snow processes: Modelling implications. Ph.D. thesis, University of Reading, $257 \mathrm{pp}$.

— distribution using terrain-based parameters to model snow accumulation and melt over a semi-arid mountain catchment. Hydrol. Processes, 16, 3585-3603, doi:10.1002/hyp.1238.

$\longrightarrow$, and — 2002: Successes and challenges on the road to an operational mass and energy balance snow model. Geophysical Research Abstracts, Vol. 15, Abstract C51D-02.

-,- , and R. Gurney, 2009: An efficient method for distributing wind speeds over heterogeneous terrain. Hydrol. Processes, 23, 2526-2535, doi:10.1002/hyp.7141.

,-- , and -2013 : Simulating wind-affected snow accumulations at catchment to basin scales. Adv. Water Resour., 55, 64-79, doi:10.1016/j.advwatres.2012.08.011.

Wiscombe, W. J., and S. G. Warren, 1980: A model for the spectral albedo of snow. I: Pure snow. J. Atmos. Sci., 37, 2712-2733, doi:10.1175/1520-0469(1980)037<2712:AMFTSA>2.0.CO;2. 